\title{
Examination of Thermal Performance for Solar Air Heater with Modified Absorber
}

\author{
Rakesh Kushwaha ${ }^{\dagger *}$, Ambreesh Prasad Shukla ${ }^{\dagger}$, Bhupendra Gupta ${ }^{\dagger}$ and Anand Bisen ${ }^{\ddagger}$ \\ ${ }^{\dagger}$ Department of Mechanical Engineering, Jabalpur Engineering College, Jabalpur-482011, India \\ ¥Mechanical Engineering, KNPC, Jabalpur, India
}

Received 02 Jan 2018, Accepted 05 March 2018, Available online 10 March 2018, Vol.8, No.1 (March 2018)

\begin{abstract}
Everyday sun delivers enormous amount of energy towards earth. Solar energy received by earth in a day is equal to total energy consumed by us in whole year. Plenty of research has been done in utilizing solar energy efficiently. Solar air heater is always a hot topic between the researchers. Different configurations of absorber plate with roughness has been prepared and tested to increase efficiency. In this article, a Computational Fluid Dynamic analysis of solar air heater having triangular shaped bodies place over the absorber plate had been performed. Enhancement in the performance of solar air heater is resulted.
\end{abstract}

Keywords: Solar Energy, Solar Air Heater, Performance, Efficiency.

\section{Introduction}

Every day, the sun radiates a massive amount of energy called solar energy. It radiates more energy in one day than the world uses in one year. This energy comes on the earth surface from within the sun itself. The sun is just like a big gas ball which is made up mostly of hydrogen and helium gas. The sun makes energy within its inner core in a process which is known as nuclear fusion. The sun energy takes a little over eight minutes to travel the 93 million miles to Earth. Solar energy travels at the speed of light, or 186,000 miles per second, or $3.0 \times 10^{8}$ meters per second. Only a small part of the visible radiant energy (light) that the sun emits into space ever reaches the Earth, but that is more than enough to supply all our energy needs. Every hour huge amount of solar energy reaches on the Earth surface to supply our nation's energy needs for a year. Solar energy is measured as a renewable energy source due to this fact.

Today, people use solar energy to heat buildings and water and to generate electricity.

Thermal analysis can be used to determine inoculants performance, apart from the traditional usage of thermal analysis to determine the percentage of carbon equivalent liquid's, carbon and silicon levels, it can also be used to monitor metallurgical processes and identify potential problems areas such as low nodule count, under-cooled graphite and carbide/chill propensity (Udroiu, 2002), (Corneli, et al, 2004), (Seidu, 2008). It can be used to predict iron shrinkage tendency and help the foundry to control scrap.

*Corresponding author: Rakesh Kushwaha

DOI: https://doi.org/10.14741/ijtt/v.8.1.3

\section{Applications of Solar Energy}

1. Industrial purposes: solar energy is used for air preheating for combustion processes, it means that thousands of applications such as drying minerals, coal, paper, bricks, food industry products, etc. mainly the drying of brown coal would be very important for power plants.

2. Crop drying: Solar energy is also used for drying of food products like grains, fruit, vegetables, meat, etc. Important benefits can be gained by harvesting the crop early and drying it with solar heat to protect it from rodents, mildew, etc. and to free the land for a second, brief crop.

3. Community and commercial purposes: Another use of solar energy for space heating for public buildings, office buildings, shopping centers.

4. Camp or camping purposes: Solar energy can also be used for space heating for emergency relief camps or military camps .space heating for recreational camping and expeditions in cold climate.

5. Solar Electricity: Solar energy can also be used to produce electricity. Two ways to produce electricity from solar energy are photovoltaic and solar thermal systems. Sometimes photovoltaic cells are called PV cells or solar cells. We are probably familiar with photovoltaic cells. Solar-powered toys, calculators, and roadside telephone call boxes all use solar cells to convert sunlight into electricity. 


\section{Solar Air Heater}

Solar air heater is a type of system in which driving outdoor air through a sealed, sun-heated collector mounted on an exterior wall or roof, returning the warmed air back to the living space. The solar collectors are made with high thermal-absorption, black aluminium plates enclosed beneath highly transmissive sun sheet. Solar air heater collects solar energy and transfer the heat to passing air which is either stored or used for space heating. There are various component used in solar air heater are as follows absorber plate, cover plate, insulation, fan. Fan is basically used for increasing the mass flow rate of air. These type of heating system is provides free and clean source of heating.

\section{Classification of Solar Air Heater}

There are various types of solar air heaters are classified as follows. In some of these, the absorber surface beneath the glazing includes overlapped, spaced, clear and black glass plates, single smooth metal sheets, stacked screens or mesh, finned metal sheets, etc. In others air passing beneath the absorber plate or underlying air passage reduces downward heat loss; and one or two covers of glass or transparent plastic provide resistance to upward convection and radiation losses. Depending on the absorber plate, air heaters can also be classified into two type; porous collector and non-porous collector.

As discussed above due to such scope of solar energy and its utilization by solar air heater many researchers give effort to improve the efficiency of SAHs. Some of these are discussed in following section of the paper.

Fangfang Menga, Ling Zhanga, Jian Liang Lic'Can Lib, Lie Xiea, Yong qiang Luo, Zhong bing Liu, have been experimentally calculated efficiency of thermoelectric warm air heater. Guofeng Yuan, Liang Hong, Xing Li, Li Xu, Wenxue Tang, Zhifeng Wang have been experimently deliberate a solar dryer system used for drying carpet. Silvina Mariana Gonzalez, Silvana Flores Larsen, Alejandro Hernandez, Graciela Lesino have perform experimental study to calculate thermal efficiency of a counter-flow double-pass solar air heater. T Bhattacharyya, R Ananda lakshmi, K. Srinivasan have been planned to studied the performance of an extruded finned plate air heating solar collector. Rudra Nandan Pramanika, Sudhansu Sekhar Sahoob, Ranjan Kumar Swain, Tara Prasad Mohapatra, Ashish Kumar Shrivastava have been experimentally studied Performance of Double Pass Solar Air Heater with Bottom Extended Surface. Tingting Zhu, Yao-hua Zhao, Yan-hua Diao, Feng-fei Li, Yuechao Deng have been experimentally investigate the performance of a novel solar air heater based on flat micro-heat pipe arrays In order to improve the efficiency of solar air heater. B N Prasada , G.N Sahb have been studied that the effect of Higher value of intensity of radiation on absorber plate of solar air heaters. Mesut Abuşka, Seyfi Şevik have planned to investigate the effect of energy, economic, made of copper and aluminum materials. Foued Chabane, Noureddine Moummi, Said Benra mache have been studied the effect of placing longitudinal fin on absorber plate of solar air heater. Khushmeet Kumar, D.R. Prajapati, Sushant Samir have been experimentally studied the effect of placing artificially roughness with 'S' shape ribs over absorber plate of solar air heater .

In order to increase efficiency of solar air heater it is very important to tear the laminar sub layer that has been formed adjacent to absorber plate. Thus air will able to pick heat directly from absorber plate. To tear this laminar sub layer different arrangement of roughness in different configurations are placed over the absorber plate. Due to presence of these roughnesses turbulence is produced and sub layer will tear off but at the same time pressure loss takes place which results in increment in pumping power and thus reduce thermo-hydraulic performance of solar air heater.

In this work, Computational Fluid Dynamic analysis of solar air heater having triangular shaped hollow bodies placed over the absorber plate is carried out Results obtained are compared with simple solar air heater, CFD analysis of simple solar air heater is also performed. Simple solar air heater without bodies is considered as Case-A and solar air heater with bodies is considered as Case-B. We found that due to presence of these bodies heat transfer area has been increased at the same time turbulence is also produced but since bodies are placed along the flow of air and in zig-zag configuration so loss of pressure is less. Procedure of CFD simulation, software used and results obtained were discussed in the subsequent section of this paper.

\section{CFD Simulation}

To perform CFD analysis of solar air heater, 3dimensional model for both the cases (with \& without bodies) were created using ANSYS Design Modeler. After preparing this model it is meshed using ANSYS Meshing Tool. This fluid domain is then solved using ANSYS FLUENT 16.0 with defined boundary conditions. Results obtained from the simulation are discussed in the next section of this paper.

\section{Result and Discussions}

Variation of temperature raise of air from inlet to outlet is shown in figures. Figure 2(a) shows that maximum temperature raise for Case-A is $22.58^{\circ} \mathrm{C}$ when the heat input is 450 watts while Figure 2(b) for Case-B maximum temperature raise is $25.34^{\circ} \mathrm{C}$ for the same heat input.

Variation of temperature of different points of absorber plate with respect to heat input for both Case$A$ and Case-B is shown in figures 1 (a) \& 1(b). Figure also shows the variation of inlet and outlet temperature of air.

Figure 3 shows comparative temperature raise for Case-A and Case-B for same heat input. From figure we can see that difference in maximum temperature raise in Case- $\mathrm{B}$ and Case- $\mathrm{A}$ is $2.76^{\circ} \mathrm{C}$ 


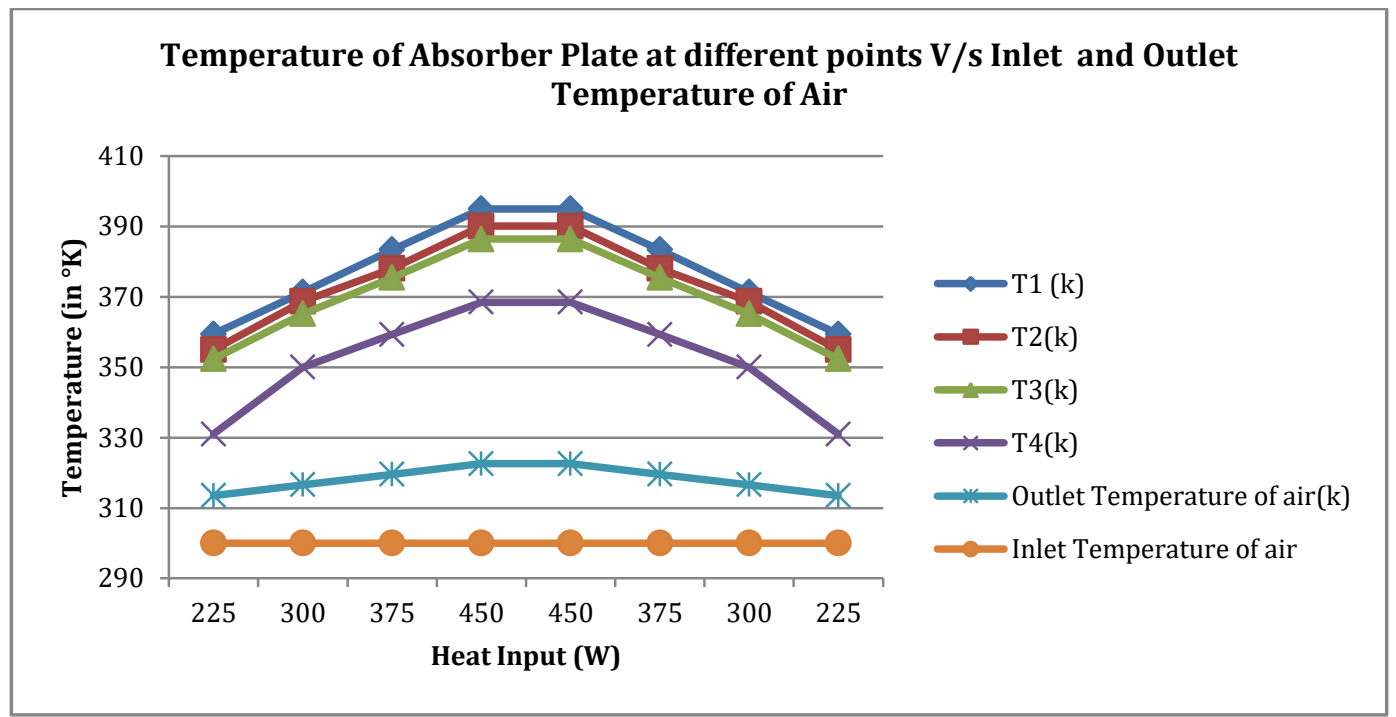

Fig. 1(a) Case-A

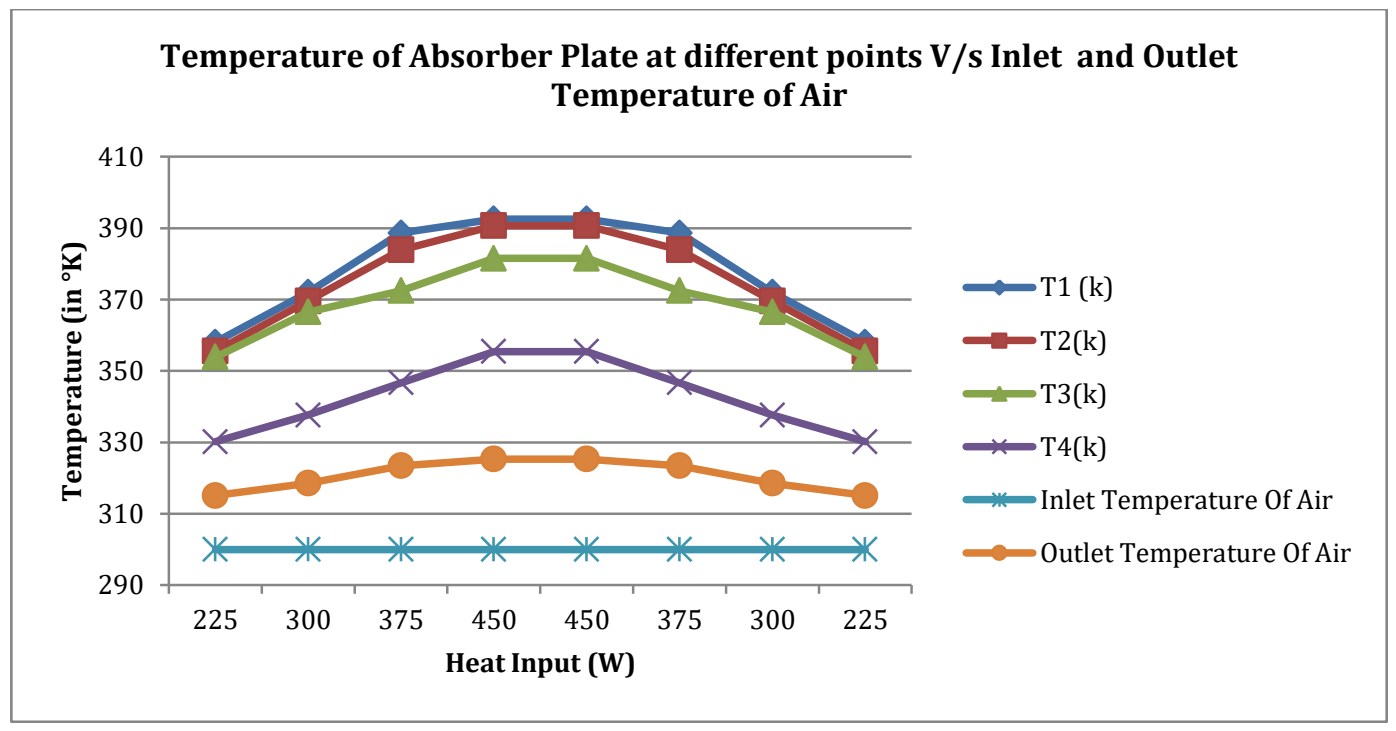

Fig. 1(b) Case-B

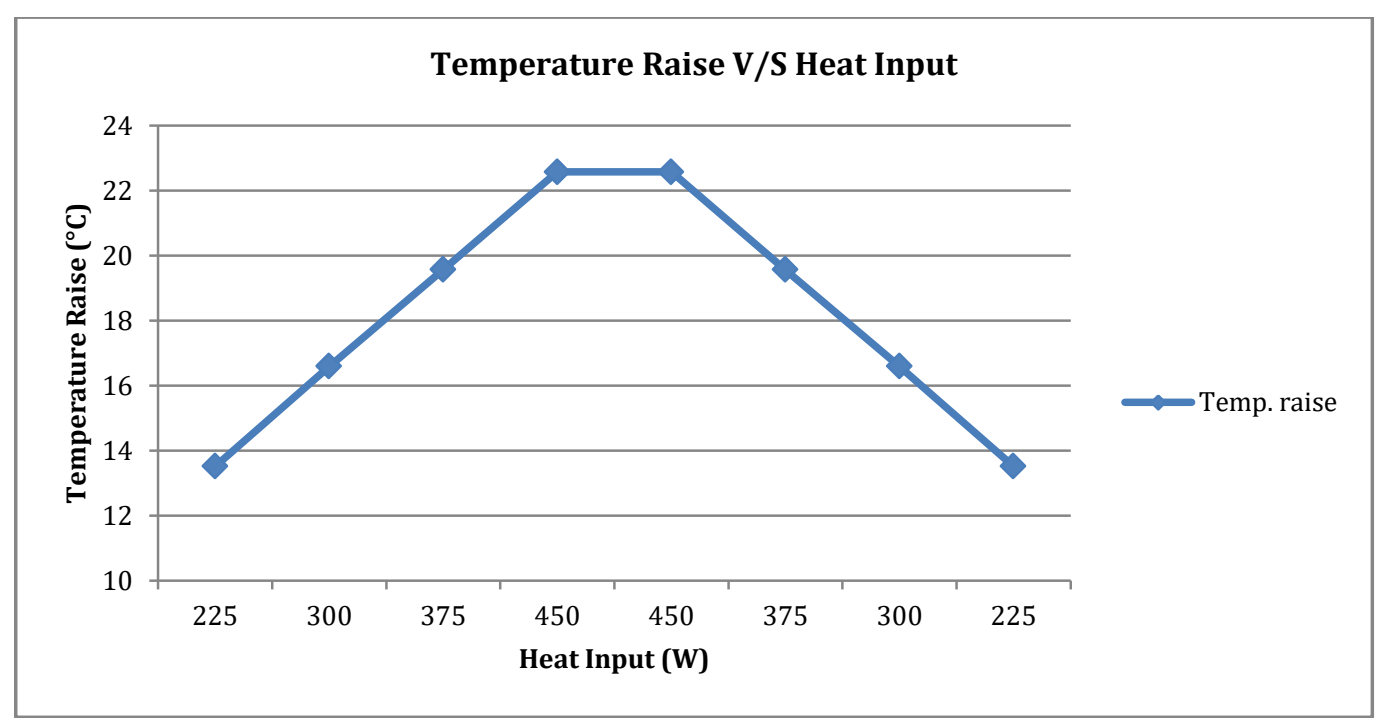

Fig. 2 (a) Case-A 


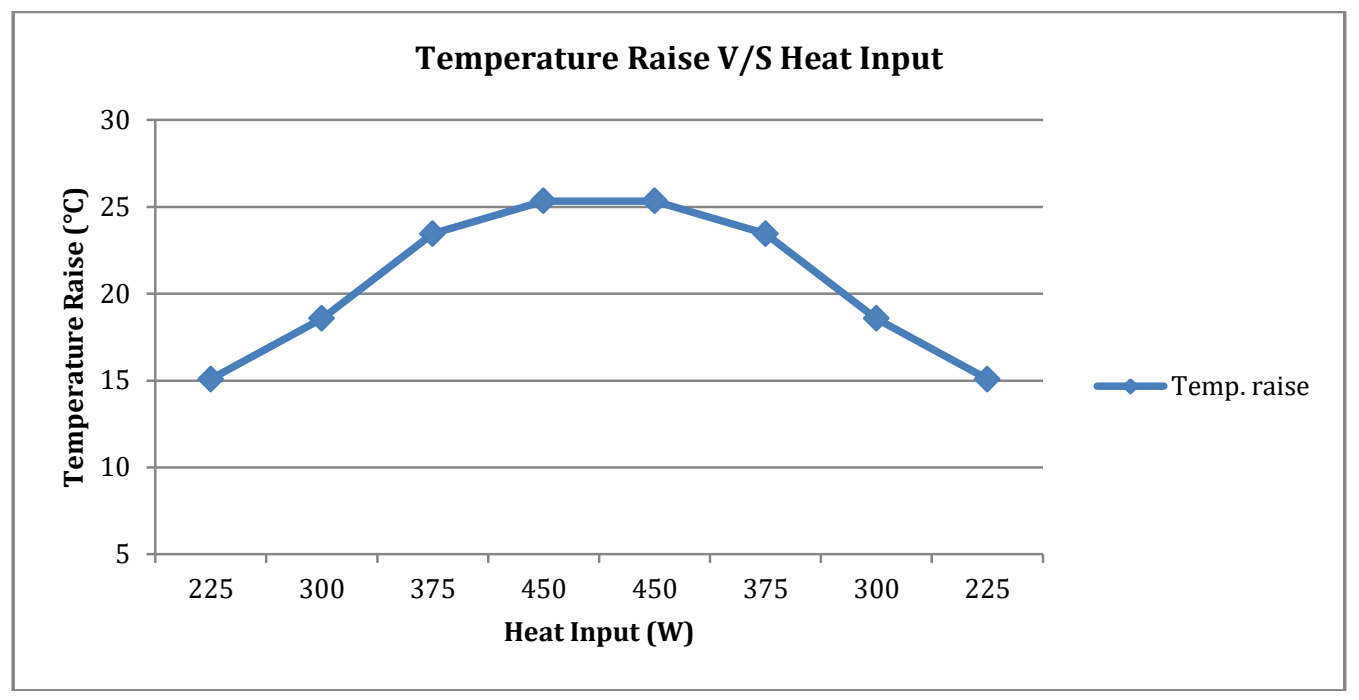

Fig. 2 (b) Case-B

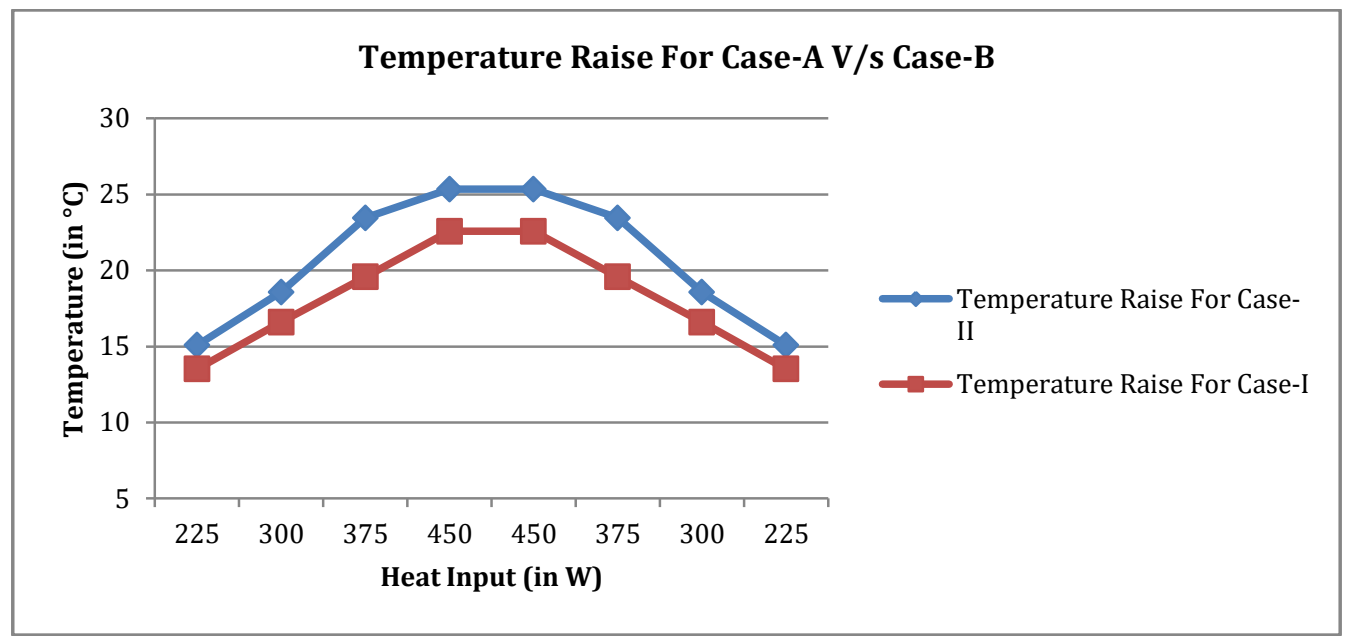

Fig. 3

\section{Conclusion}

1) Maximum temperature of air obtained at outlet of $\mathrm{SAH}$ for Case-B $325.34^{\circ} \mathrm{k}$ while for Case-A is $322.58^{\circ} \mathrm{k}$, when heat input is 450 Watts.

2) Maximum temperature raise for Case-B is $25.34^{\circ} \mathrm{C}$ while for case-A is $22.58^{\circ} \mathrm{C}$. Temperature raise for Case- $\mathrm{B}$ is increased by $2.76^{\circ} \mathrm{C}$ when compared with Case-A.

3) Increment in heat gain by air and temperature raise is observed because of presence of triangular hollow bodies.

4) Due to presence of these bodies surface area of heat transfer is increased and also due to increase in turbulence, these increments in temperature raise and heat gain by air is observed.

5) Thus it is conclude that triangular hollow bodies increase the effectiveness of solar air heater.

\section{References}

Fang fang Meng, Ling Zhang, Jian liang Lic'Can Li, Lie Xie, Yong qiang Luo, Zhong bing Liu, (2015), Investigation of thermo electric warm air heater, Energy procedia,75, 621626.

Guofeng Yuana, Liang Hong, Xing Lia, Li Xu, Wenxue Tang, Zhifeng Wang, (2015), Experimental investigation of a solar dryer system for drying carpet. Energy procedia 70 626-633.

Silvina Mariana Gonzalez, Silvana Flores Larsen, Alejandro Hernandez, Graciela Lesino, (2014), Thermal evaluation and modelling of double-pass solar air collector for air heating, Energy procedia, 57,2275-2284.

T Bhattacharyya, R Ananda lakshmi, K. Srinivasan,(2017), Heat transfer analysis of on finned plate air heating solar collector for its application in paddy drying, Energy procedia,109, 353-360.

Rudra Nandan Pramanik, Sudhansu Sekhar Sahoob, Ranjan Kumar Swain, Tara Prasad Mohapatra, Ashish Kumar Shrivastava,(2017), Performance analysis of Double Pass Solar Air Heater with Bottom Extended Surface, Energy procedia,109,331-337.

Ting-ting Zhu, Yao-hua Zhao, Yan-hua Diao, Feng-fei Li, Yuechao, (2015), Experimental investigation on performance of a novel solar air heater based on flat micro-heat pipe arrays, Energy procedia,70,146-154. 
B N Prasad, G.N Sah, (2014), Plate temperature and heat transfer characteristics of artificially roughened solar air heater, Energy procedia,62,256-269.

Mesut Abuşka, Seyfi Şevik, (2017), Energy, exergy, economic and environmental (4E) analyses of flat-plate and V-groove solar air collectors based on aluminium and copper, Solar Energy,158,259-277.
Foued Chabane, Noureddine Moummi, Said Benramache, (2014), Experimental study of heat transfer and thermal performance with longitudinal fins of solar air heater, Journal of Advanced Research,5,183-192.

Khushmeet Kumar, D.R. Prajapati, Sushant Samir, (2017),Heat transfer and friction factor correlations development for solar air heater duct artificially roughened with ' $\mathrm{S}$ ' shape ribs, Experimental Thermal and Fluid Science,82,249-261. 